\title{
PERSPECTIVE
}

\section{Comparative studies of inhaled corticosteroids in asthma}

\author{
R. Beasley*, P.J. Sterk\#, H.A.M. Kerstjens ${ }^{\natural}$, M. Decramer ${ }^{+}$
}

With inhaled corticosteroids being the mainstay of anti-inflammatory treatment in asthma, it is necessary to determine the comparative efficacy and safety of different corticosteroids delivered through different inhaler devices. Over recent years this has assumed considerable importance, with the phasing out of metered dose inhalers using chlorofluorocarbon (CFC) propellants, and with the availability of an increasing number of different dry powder devices or aerosol metered dose inhalers in which alternative hydrofluoroalkane (HFA) propellants have been used. This has led to numerous studies in which the efficacy of inhaled corticosteroid preparations, either dry powder or HFAcontaining aerosol metered dose inhalers, have been compared with the same or different inhaled corticosteroids via standard CFC-containing preparations in current use.

Although numerous study designs are available for such comparisons, that most commonly employed has been single high dose comparisons, with the lack of statistical significant differences between the two preparations being proposed to indicate equivalent efficacy.

Recently, the Editorial Board of the European Respiratory Journal (ERJ) has decided on a policy to give low priority to manuscripts of comparative studies based on such designs and inferences. The major reasons for this are that: 1) inhaled corticosteroids administered in doses 400-800 $\mu \mathrm{g}$ per day of beclomethasone dipropionate (BDP) [1-3] or budesonide [4-6] and 200-500 $\mu \mathrm{g}$ per day of fluticasone [7-9] are near the top of their dose-response curves for clinical efficacy; and 2) in double-blind dose-response studies there have seldom been statistically significant differences between different doses of inhaled corticosteroids (within the above dose range) for clinical outcomes including lung function, beta agonist use, symptoms such as nocturnal wakening or major exacerbations [1-10]. Even when four-fold differences in dose have been studied, statistically significant differences may not be observed within dose ranges of 400-1,600 $\mu \mathrm{g}$ per day of BDP or budesonide, or $200-1,000 \mu \mathrm{g}$ per day of fluticasone [1-10].

As a result, the Editorial Board has developed a policy whereby it will give low priority to the publication of studies utilizing either equal dose or two to one dose

\footnotetext{
*Dept of Medicine, Wellington School of Medicine, Wellington, New Zealand. "Leiden University Medical Center, Leiden, the Netherlands. Dept Pulmonary Diseases, University Hospital Groningen, Groningen, the Netherlands. ${ }^{+}$Respiratory Division, UZ Gasthuisberg, Leuven, Belgium.
}

R. Beasley, Dept of Medicine, Wellington School of Medicine, PO Box 7343, Wellington, New Zealand. Fax: 6443895427. comparisons of different inhaled corticosteroid drugs. As recommended in a recent review [10], the preferred study designs are double-blind placebo-controlled studies which involve: 1) a dose-response comparison in which two drugs are assessed in at least two doses, thus providing a within-trial comparison of dose-response [3]; 2) a dose-response versus one dose comparison in which the principal trial drug is given in two or more doses, while the other established corticosteroid is assessed at a single dose level that has previously been shown to be effective [11]; 3) a dose down-titration comparison in which well controlled patients reduce their dose until their asthma becomes uncontrolled, at which stage they are entered into the trial which may involve subsequent dose adjustments to determine the minimum effective dose of each drug [12]; or 4) a single dose or dose-response comparison of the efficacy/ safety ratio, utilizing measurement of validated markers of adrenal function in addition to clinical asthma outcomes [13].

While there may be difficulties with interpretation, studies which have employed the above designs are likely to be more informative than those using single dose comparisons.

Finally, while recognizing that comparisons of different inhaled corticosteroids delivered by different inhaler devices are important to determine the relative efficacy and safety of specific inhaled corticosteroid products, it is hoped that ongoing clinical research in this field is not dominated by such studies. In this respect, studies over the last decade which have examined different regimes in which inhaled corticosteroid therapy is prescribed, including early intervention $[14,15]$, starting "high" versus starting "low" dose regimes [16], pulse regimes [17], once daily schedules $[18,19]$, comparison with other medications [20, 21], combination therapy $[22,23]$ and their incorporation into an asthma self-management plan system of care [24], have added significantly to the present understanding of the best ways in which this therapy can be used. Other issues which need to be further addressed include the use of different objective markers to measure the clinical efficacy of inhaled corticosteroids [9] or to titrate their dose in long-term management [25], the determination of dose-response curves for both invasive and noninvasive markers of airways inflammation [26], and the mechanisms through which inhaled corticosteroids achieve their anti-inflammatory effects in asthma [27, 28], and consideration of their systemic side effects which enables benefit/risk ratios to be determined [13, 29]. 


\section{References}

1. Gaddie J, Reid IW, Skinner C, Petrie GR, Sinclair DJ, Palmer KN. Aerosol beclomethasone dipropionate: a dose-response study in chronic bronchial asthma. Lancet 1973; 2: 280-281.

2. Hummel S, Lehtonen L. Comparison of oral steroid sparing by high dose and low dose inhaled steroid in maintenance treatment of severe asthma. Lancet 1982; 340: 1483-1487.

3. Busse WW, Brazinsky S, Jacobson K, et al. Efficacy response of inhaled beclomethasone dipropionate in asthma is proportional to dose and is improved by formulation with a new propellant. J Allergy Clin Immunol 1999; 104: 1215-1222.

4. Johansson SA, Dahl R. A double-blind dose-response study of budesonide by inhalation in patients with bronchial asthma. Allergy 1988; 43: 173-178.

5. Busse WW, Chervinsky P, Condemi J, et al. Budesonide delivered by Turbuhaler is effective in a dosedependent fashion when used in the treatment of adult patients with chronic asthma. J Allergy Clin Immunol 1998; 102: 457-463.

6. Shapiro G, Bronsky EA, LaForce CF, et al. Doserelated efficacy of budesonide administered via a dry powder inhaler in the treatment of children with moderate to severe persistent asthma. J Pediatr 1998; 132: 976-982.

7. Chervinsky PA, van As A, Bronsky EA, et al. Fluticasone propionate aerosol for the treatment of adults with mild to moderate asthma: The Fluticasone Propionate Asthma Study Group. J Allergy Clin Immunol 1994; 94: 676-683.

8. Wolfe JD, Selner JC, Mendelson LM, Hampel F, Schaberg A. Effectiveness of fluticasone propionate in patients with moderate asthma: a dose-ranging study. Clin Ther 1996; 18: 635-646.

9. Gershman NH, Wong HH, Liu JT, Fahy JV. Lowand high-dose fluticasone propionate in asthma; effects during and after treatment. Eur Respir $J$ 2000; 15: 11-18.

10. Barnes PJ, Pedersen S. Efficacy and safety of inhaled corticosteroids: new developments. Am J Respir Crit Care Med 1998; 157: S1-S53.

11. Dahl R, Lundback B, Malo JL, et al. A dose-ranging study of fluticasone propionate in adult patients with moderate asthma. Chest 1993; 104: 1352-1358.

12. Agertoft L, Pedersen S. A randomized, double-blind dose reduction study to compare the minimal effective dose of budesonide Turbuhaler and fluticasone propionate Diskhaler. J Allergy Clin Immunol 1997; 99: 773-780.

13. Clark DJ, Lipworth BJ. Dose-response of inhaled drugs in asthma: an update. Clin Pharmacokinet 1997; 32: 58-74.

14. Haahtela T, Jarvinen M, Kava T, et al. Effects of reducing or discontinuing inhaled budesonide in patients with mild asthma. N Engl J Med 1994; 331: 700-705.

15. Selroos O, Pietinalho A, Lofroos AB, Riska H. Effect of early versus late intervention with inhaled corticosteroids in asthma. Chest 1995; 108: 1228-1234.
16. van der Molen T, Meyboom de Jong B, Mulder HH, Postma DS. Starting with a higher dose of inhaled corticosteroid in primary care asthma treatment. $\mathrm{Am}$ J Resp Crit Care Med 1998; 158: 121-125.

17. Convery RP, Leitch DN, Bromly C, Ward RJ, Bartlett G, Hendrick DJ. Effect of inhaled fluticasone propionate on airway responsiveness in treatment-naive individuals: a lesser benefit in females. Eur Respir $J$ 2000; 15: 19-24.

18. Jones AH, Langdon CG, Lee PS, et al. Pulmicort Turbohaler once daily as initial prophylactic therapy for asthma. Resp Med 1994; 88: 293-299.

19. Gagnon M, Cote J, Milot J, Turcotte H, Boulet LP. Comparative safety and efficacy of single or twice daily administration of inhaled beclomethasone in moderate asthma. Chest 1994; 105: 1732-1737.

20. Pauwels RA, Löfdahl C-G, Postma DS, et al. Effect of inhaled formoterol and budesonide on exacerbations of asthma. N Engl J Med 1997; 337: 14051411.

21. Bleecker ER, Welch MJ, Weinstein SF, et al. Losedose inhaled fluticasone propionate versus oral zafirlukast in the treatment of persistent asthma. J Allergy Clin Immunol 2000; 105: 1123-1129.

22. Chapman KR, Ringdal N, Backer V, Palmqvist M, Saarelainen S, Briggs M. Salmeterol and fluticasone propionate $(50 / 250$ microg) administered via combination Diskus inhaler: as effective as when given via separate Diskus inhalers. Can Resp J 1999; 6: 45-51.

23. Shapiro G, Lumry W, Wolfe J, et al. Combined salmeterol $50 \mu \mathrm{g}$ and fluticasone propionate $250 \mu \mathrm{g}$ in the Diskus device for the treatment of asthma. Am J Respir Crit Care Med 2000; 161: 527-534.

24. Lahdensuo A, Haahtela T, Herrala J, et al. Randomised comparison of guided self-management and traditional treatment of asthma over one year. $B M J$ 1996; 312: 748-752.

25. Sont JK, Willems LNA, Bel EH, van Krieken HJM, Vandenbroucke JP, Sterk PJ, and the AMPUL Study Group. Clinical control and histopathologic outcome of asthma when using airway hyperresponsiveness as an additional guide to long-term treatment. $\mathrm{Am}$ J Respir Crit Care Med 1999; 159: 1043-1051.

26. Wilson AM, Lipworth BJ. Dose-response evaluation of the therapeutic index for inhaled budesonide in patients with mild to moderate asthma. Am J Med 2000; 108: 269-275.

27. Wilson JW, Djukanovic R, Howarth PH, Holgate ST. Inhaled beclomethasone dipropionate down-regulates airway lymphocyte activation in atopic asthma. Am J Respir Crit Care Med 1994; 149: 86-90.

28. Laitinen LA, Laitinen A, Haahtela T. A comparative study of the effects of an inhaled corticosteroid, budesonide, and of a $\beta_{2}$-agonist, terbutaline, on airway inflammation in newly diagnosed asthma: a randomized, double-blind, parallel-group controlled trial. J Allergy Clin Immunol 1992; 90: 32-42.

29. Wong CA, Walsh LJ, Smith CJP, et al. Inhaled corticosteroid use and bone-mineral density in patients with asthma. Lancet 2000; 355: 1399-1403. 